\title{
Los sistemas de indicadores de gestión en la experiencia cooperativa de las ikastolas. Una investigación en curso
}

\author{
Management indicator systems in the cooperative \\ experience of Ikastolas. An ongoing research study
}

\author{
Unai del Burgo García y María Jesús Luengo Valderrey \\ Profesores de la UPV/EHU \\ Investigadores de GEZKI
}

DOI: $10.1387 /$ reves.20518

Fecha de entrada: 07/05/2018

Fecha de aceptación: 07/09/2018

\begin{abstract}
Sumario: 1. Introducción.-2. Las entidades de economía social y solidaria y sus características específicas en el ámbito de la gestión.-3. Los sistemas de información para la gestión en el ámbito empresarial.— 4 . Los sistemas de información para la gestión de las EESS. 4.1. La contabilidad de gestión en las entidades sin ánimo de lucro. 4.2. La contabilidad de gestión en las cooperativas. 4.3. Dualidad socioeconómica, gestión equilibrada, caos y flexibilidad.- 5 . El movimiento cooperativo de las ikastolas. 5.1. El cooperativismo de enseñanza como tercera vía en el sistema educativo. 5.2. El movimiento cooperativo de las Ikastolas. 5.2.1. Las ikastolas como centros de enseñanza de participación social. 5.2.2. Las ikastolas como organizaciones de naturaleza no lucrativa y de interés general. 5.2.3. Las ikastolas como organizaciones avanzadas en gestión. 5.2.4. Las ikastolas como movimiento social. 5.2.5. Observancia del principio "Cooperación entre cooperativas». 5.2.6. Conclusión: un objeto de investigación de gran interés.-6. Parte empírica: metodología aplicada y fases de nuestro estudio. 6.1. Perspectiva utilizadas. 6.2. Fases.-7. Fases exploratorias: el interés por parte de las ikastolas de desarrollar un sistema propio de indicadores de gestión. 7.1. Fase exploratoria, mediante metodología cualitativa (entrevista en profundidad). 7.1.1. Descripción general de la Ikastola. 7.1.2. Sistemas de contabilidad. 7.1.3. Sistemas de gestión de la calidad. 7.1.4. Gestión estratégica. 7.1.5. Conclusiones generales y pasos a seguir. 7.2. Fase exploratoria cualitativa (entrevista en profundidad) para el diseño y puesta en marcha de la fase cuantitativa (encuestas).-8. Conclusiones.-9. Referencias.
\end{abstract}

\section{Resumen:}

Las Entidades de Economía Social y Solidaria (EESS) tienen unas características especiales que las diferencian del resto de entidades empresariales: en estas en- 
tidades, los objetivos económicos son instrumentos para la consecución de sus objetivos sociales. A esta característica la denominaremos «la dualidad socioeconómica» de las EESS, es decir, la necesidad de mantener un equilibrio económico y social en la gestión de estas organizaciones.

Para gestionar de manera racional y formal la "dualidad socio-económica» o equilibrio entre lo económico y lo social en las EESS, se hace necesario diseñar sistemas de indicadores de gestión de carácter integral, holístico o equilibrado, en función de las necesidades concretas de información de las diferentes tipos de EESS: un instrumento de gestión que preservará el equilibrio entre los indicadores financieros y no financieros. El fin último de este instrumento de información es ayudar a conseguir la "gestión equilibrada» de este tipo de organizaciones (Del Burgo y otros, 2014).

El presente artículo tiene como finalidad socializar, desde el Instituto GEZKI de la UPV/EHU, una investigación empírica de carácter inductivo que abordará el tema expuesto: tras unas fases preliminares (fase descriptiva bibliográfica y fases exploratorias, descriptivas-valorativas de las prácticas reales en el ámbito de la gestión empresarial: sistemas de información formalizados para la planificación, el control y la toma de decisiones), nos centraremos finalmente en una fase propositiva o prescriptiva, donde propondremos a las diferentes entidades medidas concretas de mejora en sus sistemas de información para la gestión empresarial. Nuestra finalidad última es llegar a diseñar un sistema de indicadores de gestión que facilite la gestión equilibrada de las EESS elegidas como objeto de estudio.

En concreto, como estudio de caso múltiple, hemos elegido la experiencia cooperativa de las Ikastolas, un grupo de cooperativas de enseñanza formado por 110 centros educativos, con cerca de 56.000 alumnos y 5.000 trabajadores, constituída bajo la formula jurídica de cooperativa europea, desarrollando su actividad en la Comunidad Autónoma del País Vasco, Navarra e Iparralde. Las ikastolas se han desarrollado como un movimiento social muy arraigado en el territorio, destinado a impulsar el uso del euskara y la cultura vasca mediante un modelo de educación de calidad e innovador, organizado bajo la fórmula cooperativa y la participación de toda la comunidad educativa en cooperación con lo publico. En el ámbito de la gestión, a partir de la década del 2000 las ikastolas han innovado también en las áreas de la planificación, el control y la toma de decisiones, sobre todo mediante la implementación de diferentes modelos de gestión de la calidad total (Del Burgo, 2013).

Es por todo ello, por lo que opinamos que las Ikastolas son un objeto de estudio sumamente interesante para analizar el fenómeno de gestión que pretendemos entender y mejorar en el seno de las EESS: un grupo auto-coordinado de organizaciones sin ánimo de lucro y de carácter social, con intención firme de mejorar sus procesos de gestión.

\section{Palabras clave:}

Economía social y solidaria, control de gestión, sistemas de indicadores de gestión, calidad total, Balanced Scorecard, Cuadro de Mando Integral, cooperativas de enseñanza, Ikastolas. 


\begin{abstract}
:
Solidary and Social Economy Entities (SSEE) bear special features that set them apart from other business entities. With these entities, economic objectives are instruments to achieve their social objectives. We call this characteristic "the socioeconomic duality" of SSEEs, meaning the need to keep a socioeconomic balance in managing these organisations. To rationally and formally manage this "socioeconomic duality" or balance between the economic and the social aspect of SSEEs, it is necessary to design management integrator systems that are integral, holistic or balanced, based on the specific informational needs of different kinds of SSEEs: a management instrument that keeps the balance between financial and non-financial indicators. The purpose of this informational instrument is to help attain "balanced management» for this kind of organisation (Del Burgo et al, 2014). This article aims, through the UPV/EHU GEZKI Institute, to socialise an empirical inductive research work to address the issue at hand: after preliminary phases (bibliographical descriptive phase and exploratory phases, descriptive-valuation phases of real practises in company management: formalised information systems to plan, control and make decisions), we finally focus on a phase to propound or recommend, proposing specific measures to different entities to improve their information systems for business management. Our ultimate goal is to design a management indicator system to facilitate balanced management for the SSEEs selected as object of study. Specifically, as a multiple case study, we selected the Ikastolas' cooperative experience, a group of teaching cooperatives comprising 110 educational centres, with approximately 56,000 students and 5,000 employees, established under the European cooperative legal formula, conducting its activity in the Autonomous Community of the Basque Country, Navarre and Iparralde. Ikastolas have developed as a deeply-rooted social movement in the territory, designed to foment the use of the Basque language and culture by means of a quality, innovative education model, organised under a cooperative, participatory formula for the entire educational community in cooperation with the public. As far as management is concerned, beginning in the 2000s, Ikastolas have also innovated in planning, control and decision-making, especially by implementing different total quality management models (Del Burgo, 2013). This is why we believe that the Ikastolas are a highly interesting study target to analyse the phenomenon of management that we aim to understand and improve with SSEEs: a self-coordinated group of not-for-profit social organisations, with the firm intent to improve their management processes.
\end{abstract}

\title{
Keywords:
}

Social and solidary economy, management control, management indicator systems, total quality, Balanced Scorecard, Comprehensive Dashboard, teaching cooperatives, Ikastolas. 


\section{Introducción}

Son pocos los ámbitos de la empresa que sean más importantes que la medición de sus procesos y resultados. Más allá de la rendición de cuentas, desde el punto de vista de la gestión, los sistemas de información formalizados son totalmente necesarios para la planificación, control y toma de decisiones en el ámbito empresarial.

Entre los sistemas de información formalizados, destaca uno entre todos ellos: la contabilidad. Comúnmente, al hablar de contabilidad nos referimos a la contabilidad tradicional de carácter económico-financiero: la contabilidad financiera y la contabilidad de gestión. La primera, destinada sobre todo a la rendición de cuentas. La segunda, dividida en dos ramas casi exclusivas de la gestión interna de las organizaciones, la contabilidad de costes y la contabilidad presupuestaria.

Esta contabilidad tradicional no mide los resultados empresariales en variables clave en el largo plazo, como son las variables no financieras. Es incapaz para realizar dicho cometido. Por ello, la contabilidad tradicional ha evolucionado hacia la denominada contabilidad de dirección estratégica (Del Burgo y Malles, 2010). Es en esta última donde se han desarrollado los diferentes sistemas de indicadores para la gestión empresarial de carácter multidimensional (financiero y no financiero); entre ellos, el más famoso, el Cuadro de Mando Integral (CMI) o «Balanced Scorecard». No obstante, también podemos encontrar otros instrumentos para la gestión de la información financiera y no financiera en áreas como la contabilidad social o la medición de la responsabilidad social corporativa y la gestión de la calidad total (Del Burgo y Luengo, 2013).

En comparación con las tradicionales organizaciones empresariales de carácter capitalista, las Entidades de Economía Social y Solidaria (EESS) tienen unas características especiales que las diferencian del resto de entidades empresariales: al igual que en las entidades de carácter público, los objetivos y fines económicos de las EESS son instrumentos para la consecución de sus fines últimos, a saber, los objetivos de carácter social. Lo económico es un instrumento sumamente importante, pero únicamente un instrumento, al fin y al cabo. A esta característica la denominaremos «la dualidad socio-económica» de las EESS, es decir, la necesidad de mantener un equilibrio económico y social en la gestión de estas organizaciones.

Para gestionar de manera racional y formal la «dualidad socio-económica» o equilibrio entre lo económico y lo social en las EESS, se hace necesario diseñar sistemas de indicadores de gestión de carácter integral, holístico o equilibrado, en función de las necesidades concretas de información de las diferentes tipos de EESS: un instrumento de gestión que preservará el equilibrio entre los indicadores financieros y no financieros. El fin úl- 
timo de este instrumento de información es ayudar a conseguir la «gestión equilibrada» de este tipo de organizaciones (Del Burgo y otros, 2014).

Existen ciertos instrumentos, ya mencionados anteriormente, que pueden servir de modelo, tales como el CMI o sistemas de indicadores de gestión inspirados en el modelo EFQM. No obstante, cada organización o grupo diferenciado de EESS tiene que diseñar sus propios sistemas de indicadores de gestión según sus necesidades informativas. Aquí radica el fundamento último de la investigación que presentamos en el presente artículo: el estudio de un caso concreto.

La finalidad del presente artículo es socializar una investigación en curso: proponemos realizar un estudio empírico de carácter inductivo, que tras unas fases preliminares, se centre finalmente en una fase prepositiva, donde propondremos a las diferentes entidades medidas concretas de mejora en sus sistemas de información para la gestión empresarial. Nuestra finalidad última es llegar a diseñar un sistema de indicadores de gestión que facilite la gestión equilibrada de las EESS elegidas como objeto de estudio.

En concreto, hemos elegido, como estudio de caso múltiple, la experiencia cooperativa de las Ikastolas: éstas se han desarrollado como un movimiento social muy arraigado en Euskal Herria, destinado a impulsar el uso del euskara y la cultura vasca mediante un modelo de educación de calidad e innovador, organizado bajo la fórmula cooperativa y la participación de toda la comunidad educativa en cooperación con lo público, todo ello organizado bajo los parámetros fijados por ciertos modelos de gestión avanzada (Del Burgo, 2013).

Es por todo ello por lo que opinamos que las Ikastolas son un objeto de estudio atractivo para analizar el fenómeno de gestión que pretendemos abordar. Nuestra finalidad es entender y mejorar este "fenómeno empresarial». Para ello, desde GEZKI vamos a trabajar en estrecha cooperación con las propias ikastolas, compartiendo con ellas tanto la valoración de sus prácticas en materia de gestión, como las medidas de mejora que les vamos a proponer. El producto final de la investigación será un sistema de indicadores que facilite la gestión equilibrada del dualismo socio-económico de este tipo de EESS.

En el presente artículo, tras abordar una síntesis del marco teórico de nuestro proyecto de investigación (apartados $2 .^{\circ}, 3 .^{\circ}, 4 .^{\circ}$ y $5 .^{\circ}$ ), pasaremos a explicar cómo analizaremos en la realidad las cuestiones señaladas en esa misma parte teórica: presentaremos la metodología empírica propuesta y sus fases, y expondremos los resultados de la fase empírica primera que se corresponde con un estudio exploratorio medidor de las potencialidades reales de nuestra investigación. Finalmente, en las conclusiones del presente documento, haremos una síntesis de las claves de nuestro proyecto de investigación en curso. 


\section{Las entidades de economía social y solidaria y sus características específicas en el ámbito de la gestión}

Encontramos multitud de términos en la literatura científica para delimitar el concepto de Tercer Sector, y ello dificulta enormemente dicha labor de delimitación. Encontramos tres conceptos principales que tratan de aclarar este tercer sector, diferenciándolo de la economía pública y de la economía capitalista (Sajardo y Chaves, 2006: 91-92): el sector no lucrativo (Salomon y Aneheier, 1992), la economía social (Monzón, 2006: 11-12) y la economía solidaria (Borcaga y Alceste 2003: 41-42).

En el presente trabajo, partiremos de un punto de vista integrador en relación a todos estos conceptos, de manera que vamos a utilizar el término Economía Social y Solidaria para aglutinar tanto a las entidades tradicionales situadas en la Economía Social (tales como las cooperativas, sociedades laborales y mutualidades), como a las organizaciones sin ánimo de lucro (asociaciones y fundaciones). Además, incluiremos también a las nuevas formas de emprendimiento social encuadradas en la Economía Solidaria.

La razón de que utilicemos dicho punto de vista integrador, es que, en nuestra opinión, todas las organizaciones citadas poseen la misma naturaleza específica en su gestión empresarial: en comparación con las tradicionales organizaciones empresariales de carácter capitalista, las EESS tienen unas características especiales que las diferencian del resto de entidades empresariales. Al igual que en las entidades de carácter público, los objetivos y fines económicos de las EESS son instrumentos para la consecución de objetivos de carácter social, de carácter mutualista en algunos casos (servicio a sus socios) y de interés general en otros (servicio a la sociedad). De esta manera, las variables sociales cobran una importancia clave en la gestión de las EESS, ya que nos informan sobre la consecución de sus fines sociales. Ello no quiere decir que las variables económico-financieras (tradicionalmente, las variables clave en las entidades de corte capitalista) no tengan una importancia notoria en las EESS. No obstante, no son el fin último de este tipo de entidades, sino que son un instrumento para asegurar la consecución de sus fines sociales.

Esta dialéctica entre fines sociales y económicos se da de la manera más contundente posible en las cooperativas, ya que por un lado son empresas y por otro, asociaciones de personas (Agirre, 2001: 100): los fines económicos son importantes, pero los sociales son imprescindibles. Esto es lo que denominaremos a efectos del presente trabajo, la dualidad socio-económica de las EESS, que entiende lo económico supeditado a lo social. Dicha dualidad tiene que ser gestionada de manera equilibrada. Con esto hacemos referencia a la "gestión equilibrada» de las EESS (Cid, 2005). 
Dicha gestión equilibrada puede realizarse mediante métodos informales (cultura empresarial, intuición personal...) o mediante métodos formales. Con éstos últimos hacemos referencia a los sistemas formalizados de información empresarial, y serán los que vamos a analizar en este trabajo.

\section{Los sistemas de información para la gestión en el ámbito empresarial}

Son pocos los ámbitos de la empresa que sean más importantes que la medición de sus procesos y resultados. Más allá de la rendición de cuentas, desde el punto de vista de la gestión, los sistemas de información formalizados son totalmente necesarios para la planificación, control y toma de decisiones en el ámbito empresarial.

El Control de Gestión es el conjunto de instrumentos que posee la dirección de la empresa para asegurar y controlar el cumplimiento de sus objetivos. Mediante dichos instrumento, la dirección planifica y mide los cometidos y rendimientos de las personas y grupos de la organización: la dirección controla los resultados previstos, calculando las desviaciones ocurridas con respecto a los resultados realmente existentes. Para dicho control de la gestión, la dirección tiene que disponer de la información necesaria, de calidad y de manera oportuna, es decir, la información justa y necesaria en el momento oportuno (Amat, 2003).

Entre los sistemas de información necesarios para desempeñar el control de la gestión, la contabilidad es la disciplina más importante de la que dispone la dirección. Podemos clasificar el concepto de contabilidad en tres tipos o ramas (Azkue y Zubiaur, 1996; Heras, 2004: 268):

i. Contabilidad financiera: es la contabilidad preparada para la rendición de cuentas de la empresa, en el ámbito económico-financiero. De hecho, dicha información es utilizada por terceras personas ajenas a la empresa, para valorar la misma desde el punto de vista económico-financiero (inversores, acreedores, administraciones públicas, sindicatos...). No obstante, la información dada por la contabilidad financiera también es utilizada por la dirección para tener una fotografía general de la situación económica-financiera de la empresa, y poder así tomar decisiones de manera racional. Hablamos del análisis de los estados financieros.

ii. Contabilidad de gestión: se trata de la contabilidad desarrollada para dar apoyo informativo a la toma de decisiones sobre la gestión operativa y táctica de la organización, ofreciendo a la dirección información económica adecuada y oportuna, analizada e interpre- 
tada «a medida» de las necesidades de la organización, sin modelos estandarizados como es el caso de la contabilidad financiera. Hablamos de la contabilidad de costes y la contabilidad presupuestaria.

iii. Contabilidad de dirección estratégica: es la información sistematizada para la toma de decisiones a largo plazo, es decir, la toma de decisiones estratégicas. Su función es la planificación y el control estratégicos. Dicha contabilidad abarca todo el proceso estratégico de la organización: el diagnóstico continuo de la empresa (interno y externo), formulación de objetivos y elección de la estrategia adecuada para su consecución, planificación, programación, presupuestación a largo plazo y control de resultados. El máximo exponente de la contabilidad de dirección estratégica es el denominado Cuadro de Mando Integral o Balanced Scorecard, además de los sistemas de indicadores de gestión del modelo EFQM y otros modelos de Calidad Total (Álvarez y Blanco, 2001).

De cara a la gestión empresarial, y no tanto de cara a la rendición de cuentas, la contabilidad es el sistema de información que facilita la planificación, el control de la gestión y la toma de decisiones en el ámbito interno organizacional, de manera que la contabilidad recopila, sistematiza, analiza, interpreta y comunica la información necesaria y oportuna para facilitar los procesos citados. Estamos hablando del marco contable para las decisiones estratégicas en el ámbito empresarial (AECA, 2003a: 21).

No obstante, al hablar de contabilidad, nos viene inevitablemente a la mente la información económico-financiera. Lo cierto es que este tipo de contabilidad económico-financiera tiene importantes problemas para apoyar la toma de decisiones estratégica o largo plazo en el ámbito empresarial. Lo más importante no suele medirse únicamente mediante variables económico-financieras. Para la medición «a priori» (planificación) y «a posteriori» (control) de cualquier organización, además de las tradicionales magnitudes monetarias, es necesario controlar otras variables de carácter más multidimensional o integral (AECA 2001; Esther, 2003).

La contabilidad financiera y la contabilidad de gestión, es decir, los tradicionales sistemas de información contable, tienen serios problemas y obstáculos para planificar y controlar la gestión en el entorno dinámico actual, donde la medición de variables no monetarias como la calidad de lo ofertado y la satisfacción de las personas, se convierten en elementos estratégicamente más importantes que las variables meramente monetarias (AECA, 2002: 17-20; Amat, 2003: 213-236).

Por ello, la contabilidad ha evolucionado hacia la medición de variables multidimensionales de carácter no monetario, sin dejar de lado el control 
continuo sobre las variables económico-financieras. Para dicha evolución, la contabilidad ha diseñado los sistemas de indicadores de gestión de carácter integral (Blanco, 2008: 255), que incluyen indicadores monetarios y no monetarios, tanto cuantitativos como cualitativos.

\section{Imagen 1}

Marco contable para la toma de decisiones estratégicas

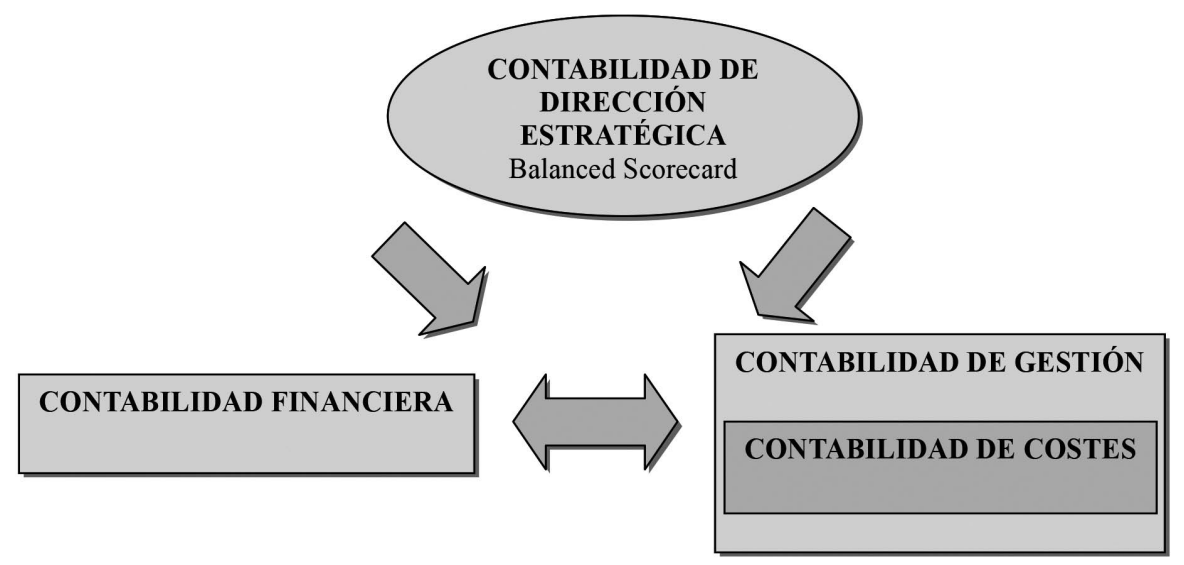

Fuente: AECA, 2003a: 33).

En esencia, lo cualitativo se convierte en estratégico en el ámbito empresarial mercantil y capitalista, por encima de lo meramente monetario. Un ejemplo de la importancia de lo cualitativo aparece reflejado en el desarrollo que han tenido en las últimas décadas los modelos de gestión de la calidad total. El exponente europeo en este ámbito de la gestión empresarial es el modelo EFQM, una propuesta de modelo de gestión de la calidad total ideado por la organización privada European Foundation for Quality Management. El objetivo de dicho modelo es desarrollar los sistemas de gestión de las entidades en función de la mejora continua y la auto-evaluación con respecto a los principios de la excelencia empresarial (Aguirre y otros, 2006: 319).

En lo que al presente trabajo se refiere, no nos interesa citar el EFQM y sus sistema de indicadores desde el punto de vista de la rendición de cuentas o mejor dicho, desde la interpretación de dicho modelo como certificación, sino desde el punto de vista del control de la gestión. De hecho, el modelo EFQM y cualquier modelo de gestión de la calidad total, se constituyen como modelos holísticos, multidimensionales o integrales de control de la gestión (Dahlgaard-Park, 2008: 111-112). 
Así, estos modelos van más allá de la certificación y de los premios: son complejos sistemas de indicadores de gestión empresarial de carácter integral, destinados a la mejora continua mediante la medición de procesos y resultados. Instrumentos adecuados para la autoevaluación y para la comparación con respecto a un ideal prefijado (Blanco, 2008: 334). El modelo EFQM se apoya en sistemas de información formalizados (Luengo, 2009: 102), es decir, en sistemas de indicadores de gestión, instaurando una cultura de toma de decisiones racional fundamentada en el análisis de datos y limitando la toma de decisiones de carácter intuitiva. (AECA, 2003b: 33).

Tal y como afirma (Amat, 2003: 34), cuanto mayor es la complejidad de la organización (muchas veces en función de su tamaño), se hace más necesario contar con sistemas de información para la gestión de carácter formalizados, recurriendo de forma más limitada a la intuición o a otros métodos de control empresarial.

\section{Los sistemas de información para la gestión de las EESS}

Si bien el apartado primero nos hemos posicionado a favor de una visión integradora del Tercer Sector (bajo el término «Economía Social y Solidaria»), a la hora de analizar la gestión de las EESS, tenemos que dividir dicho análisis en los dos subgrupos mayoritarios: las entidades sin ánimo de lucro y las cooperativas. La razón de esta división es que la literatura científica en materia de gestión de EESS no realiza un análisis integrador de dicha disciplina, sino que se centra en los dos grupos que acabamos de señalar.

\subsection{La contabilidad de gestión en las entidades sin ánimo de lucro}

Para lograr sus objetivos, las entidades sin ánimo de lucro deben gestionarse de manera económicamente eficiente y socialmente eficaz. Para ello, deben diseñar y utilizar sistemas de información de gestión propios adaptados a sus necesidades informativas (AECA, 2001: 13).

Según (Drucker, 1990), las entidades sin ánimo de lucro debieran aprender de las tradicionales empresas mercantiles capitalistas en lo que al diseño e implementación de sistemas de información formalizados se refiere, dado el contexto socioeconómico altamente competitivo en el que desarrollan estas su actividad.

En este sentido, analizaremos las diferentes herramientas que la contabilidad de gestión aporta al sector no lucrativo, en concreto, la contabilidad de costes, la contabilidad presupuestaria y los sistemas de indicadores de gestión. 
En relación a la contabilidad de costes, los expertos rechazan la posibilidad de diseñar un único sistema de contabilidad de costes para el sector no lucrativo (AECA, 2001: 28), dado que las organizaciones de este sector abarcan multitud de actividades económicas, tales como educación, servicios sociales, reciclaje, etc. Además, se recalca expresamente que la contabilidad de costes no difiere en el sector sin ánimo de lucro con respecto al sector lucrativo (AECA, 2001: 31). De hecho, lo que caracteriza a cada sistema de contabilidad de costes no es la forma jurídica de cada organización, sino la naturaleza de su propia actividad (industrial, servicios...). No obstante, algunos expertos si proponen genéricamente ciertos tipos de contabilidad de costes para las organizaciones sin ánimo de lucro, tales como los sistemas de contabilidad de costes por programas (AECA, 2001: 38-40) y el sistema de costes por actividades o ABC (Bellostas y otros, 2008: 102).

En lo que a la contabilidad presupuestaria se refiere, los expertos tienen varias propuestas para aplicar al sector, tales como: los presupuestos por programas (AECA, 2001: 49-67), asegurando la participación de los responsables de cada proyecto en la confección del presupuesto; presupuestos de base cero, de manera que cada partida de gasto se debe justificar para que sea incluida en el presupuesto, a diferencia del presupuesto incremental, en el que apoyándonos en los datos históricos del ejercicio anterior, las partidas se incrementan en un porcentaje dado (AECA, 2001: 49-51).

No obstante, la contabilidad presupuestaria tiene ciertas diferencias en su aplicación al sector no lucrativo (AECA, 2001: 50-51):

- Tal y como ocurre en el sector público, en el sector no lucrativo el presupuesto depende directamente de la financiación que podamos atraer: es decir, el nivel de gasto de cada proyecto o programa depende de la financiación lograda para su ejecución. Los ingresos limitan el presupuesto. Por ello, en primer lugar calculamos los ingresos y a continuación, los gastos.

— Las organizaciones sin ánimo de lucro se centran en lograr sus objetivos sociales, y por lo tanto, en mejorar la calidad del servicio ofertado. Por tanto, las partidas de gastos son esenciales (nos muestras el nivel de desarrollo de la actividad social), no tanto la búsqueda única de beneficio. A pesar de esta idea, es necesario recalcar que la eficiencia económica es esencial.

Las variables económico-financieras podrán ser una limitación o una ayuda para el desarrollo de la actividad no lucrativa, pero raras veces serán su componente principal (AECA, 2001: 74). En este sentido, según (Kaplan y Norton, 2001), la medición de las variables económico-financieras no reflejan el logro de objetivos en el sector no lucrativo. Tal y como seńa- 
lábamos en el apartado primero, la dificultad principal de las EESS en relación a sus sistemas de medición, es poder controlar las variables no financieras, tales como la participación del voluntariado, ya que dicha medición es imposible con los métodos de contabilidad de gestión "tradicionales», tales como los sistemas de costes o el proceso presupuestario, que acabamos de analizar (Soldevila 2000: 88; AECA 2001: 41-44; Parker, 2000: 309-319).

Por ello, es necesario implementar en las entidades sin ánimo de lucro, sistemas de indicadores de gestión de carácter multidimensional u holístico (AECA, 2001: 87-114), adaptados a las organizaciones, y que midan tanto variables no financieras como financieras (AECA, 2001: 68-69; Soldevila 2000: 92, 120; Bellostas y otros, 2008: 106).

Una propuesta concreta para el sector es la utilización del Balanced Scorecard de Kaplan y Norton (AECA 2001: 69, 75), adaptado a este tipo de entidades: genéricamente, el Balanced Scorecard, se centra en las personas, en sus capacidades y en los procesos de producción de los bienes o servicios, y no tanto en el resultado económico-financiero. Diseńado en 1992 por el profesor de Harvard R. Kaplan y por el consultor de Boston D. Norton, el Balanced Scorecar o Cuadro de Mando Integral es un sistema de indicadores de gestión estratégica, que se divide en 4 perspectivas, conectadas entre ellas (Kaplan y Norton 1996): finanzas, clientes, procesos y capacidades/recursos. Cada perspectiva se controla mediante indicadores, 25 como máximo. Un sistema de indicadores integral y sintético, que en su concepción general, actúa de la siguiente manera: si una entidad invierte en las personas y sus capacidades, podrá mejorar sus procesos, maximizando la satisfacción de sus clientes y finalmente, logrando los mejores resultados económico-financieros.

La idea es re-diseñar el Balanced Scorecad de kaplan y Norton a las entidades sin ánimo de lucro, de la siguiente manera (Santos y Fidalgo 2002: 18; Amat y Soldevila 1999; Soldevila 2000: 138; Soldevila y Amat, 2002): si una entidad sin ánimo de lucro invierte en las personas y sus capacidades, podrá mejorar sus procesos, mejorando sus resultados económico-financieros y finalmente, logrando su fin último, es decir, la maximización de la satisfacción de sus "clientes», que en esta adaptación del modelo general pasan a denominarse «usuarios» o «sociedad», según el fin de la propia entidad.

Como conclusión, se hace necesario integrar las herramientas tradicionales de la contabilidad de gestión (sistemas de costes y contabilidad presupuestaria) en un Balances Scorecard adaptado a la naturaleza de las entidades sin ánimo de lucro, de manera que mediante el control de las variables financieras y no financieras, se logre que estas entidades sean económicamente eficientes y socialmente eficaces. 


\section{Imagen 2}

Adaptación del Balanced Scorecar a las entidades sin ánimo de lucro
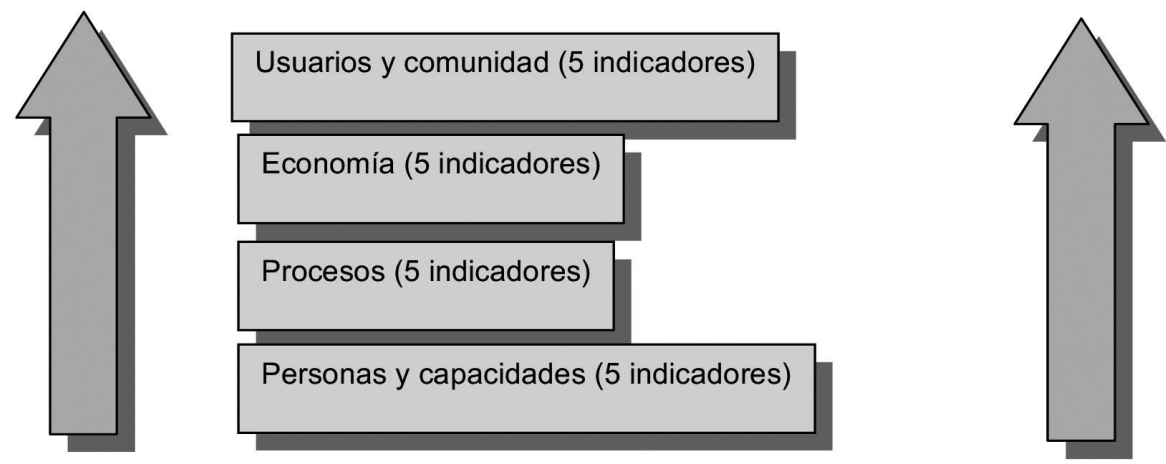

Fuente: Soldevila 2000: 138.

\subsection{La contabilidad de gestión en las cooperativas}

En la literatura científica, no se hace referencia a herramientas tradicionales de contabilidad de gestión (costes y presupuestos), dado que la naturaleza autogestionaria de las cooperativas no influye en sus variables monetarias y por tanto, tampoco en el diseño de sus sistemas de información económico-financieros para su gestión.

No obstante, los valores y principios cooperativos sí influyen en las nuevas herramientas de la contabilidad de gestión. De hecho, las variables que caracterizan a las cooperativas debieran medirse para su gestión y control, y dada la imposibilidad de las tradicionales herramientas económico-financieras para dicha labor, opinamos que los sistemas de indicadores de gestión son la clave. Más aun, según algunos autores, los valores y principios cooperativos conectan fácilmente con los principios de la denominada «nueva» contabilidad de gestión (Cabailero y FernándezFeióo, 1997):

- Principio de adhesión voluntaria: en la practica, este principio promueve la estabilidad de los socios y su integración en la cooperativa, por lo que se facilita el calculo de ciertas partidas de gasto en los procesos presupuestarios.

- Gestión democrática: la participación e implicación de las personas es esencial y estratégica en entornos complejos como el actual, por lo que el control de dichas variables es ineludible. Dichas variables son característica intrínseca de las cooperativas (Agirre, 2001), por 
lo que su control también. Aquí aparece el papel de la nueva contabilidad de gestión.

-Educación, formación e información: para fomentar la implicación de las personas en la cooperativa, la información es esencial. En el caso de una cooperativa inmersa en un estilo cultural autogestionario, los socios debieran participar en los procesos de diseño y utilización de las herramientas de contabilidad de gestión.

- Cooperación entre cooperativas: para el caso de la toma de decisiones conjuntas (como grupo) o para la comparación de resultados entre cooperativas para evaluar y direccionar la gestión de la propia, las nuevas herramientas de contabilidad de gestión son instrumentos interesantísimos.

— Interés por la comunidad: quizás, la relación más importante entre Valores y Principios Cooperativos y la contabilidad de gestión, se da en el ámbito de la Responsabilidad Social Corporativa, dado la importancia del principio de interés por la comunidad, que tiene que ser medido y controlado adecuadamente.

Ligado al control del principio cooperativo de interés por la comunidad, cobran gran relevancia instrumentos de rendición de cuentas ligados a la Responsabilidad Social Corporativa, como el Balance Social y las Memorias de Sostenibilidad. No obstante, más allá de la rendición de cuentas, estos instrumentos también pueden ser utilizados para la auto-evaluación de la gestión (Mugarra, 1995: 8, Mugarra y Enciso, 1997: 243-249; Mugarra, 2000: 224-275; Mugarra, 2002: 69-87, Mugarra, 1998: 324-390), integrándose con el resto de sistema de información para el control del desempeño y el rendimiento (Garcia Echevarria, 1981). Así, mediante la implementación de estos instrumentos, las cooperativas podrán gestionar (medir y controlar) las variables cooperativas que ciertamente son de gran importancia estratégica en el entorno dinámico y complejo actual, logrando como apuntábamos en el apartado sobre la contabilidad de gestión de las entidades sin ánimo de lucro, la eficiencia económica y la eficiencia social (Agirre, 2001).

De forma genérica, los sistemas de control de gestión deben integrarse con el concepto de Responsabilidad Social Corporativa (Durden, 2008). En cooperativismo, esta integración tiene que tener en cuenta necesariamente los Valores y Principios Cooperativos (Mugarra, 2005b: 290).

Aquí nos encontramos con un concepto peculiar, «accounting for cooperative-goals», es decir, la necesidad de desarrollar sistemas de contabilidad o medición que controlen los objetivos de la cooperativa en relación a sus valores y principios (Web, 2005). En concreto, estos sistemas de contabilidad "para los objetivos cooperativos» se han materializado en sistemas de indicadores de gestión multidimensionales, integrales u holísticos. 
Y esto es lo que propone (Cid, 2005) con su «The Blended Scorecard», una variante del Cuadro de Mando Integral de Kaplan y Norton adaptada a las cooperativas: introducir en el Cuadro de Mando Integral indicadores que midan los principios cooperativos, como medio de gestionar la dualidad cooperativa (al mismo tiempo, empresa y asociación de personas).

\subsection{Dualidad socioeconómica, gestión equilibrada, caos y flexibilidad}

Hasta ahora hemos señalado las especificidades en el ámbito de la gestión de las EESS: su dualidad socioeconómica y la necesidad de realizar una gestión equilibrada teniendo en cuenta que lo económico es un medio para lo social. Para dicha gestión hemos propuesto los sistemas de indicadores de gestión de carácter integral.

Ahora tenemos que enmarcar estos «nuevos» instrumentos de contabilidad de gestión en el entorno complejo y dinámico actual. La sociedad en la que vivimos está inmersa en un caos, en una complejidad a la que las EESS no son ajenas. Para moverse en ese caos la flexibilidad es una característica elemental. Por ello, los sistemas de información para la gestión tienen que ser coherentes con esa flexibilidad.

Por consiguiente, los sistemas de información para la gestión de las EESS tienen que ser flexibles, ágiles, simples y adaptados a las necesidades informativas de cada organización, por lo que no pueden caer en la burocracia, en instrumentos de medición, control y gestión excesivamente complejos y rígidos. Además, estos instrumentos de medición formalizados tienen que convivir con otras herramientas de gestión no formalizadas, como son la intución y la cultura empresarial, de manera que la toma de decisiones sea lo más rápida, fluida y participativa posible.

\section{El movimiento cooperativo de las ikastolas}

Dentro del marco teórico hay que hacer referencia directa a las Ikastolas, dado que es el objeto «empírico» de nuestro estudio. Analizaremos en primer lugar el cooperativismo de enseñanza en general, para luego pasar directamente al estudio del movimiento cooperativo de las Ikastolas.

A pesar de su importancia cuantitativa y cualitativa, la naturaleza cooperativa de las Ikastolas no ha sido investigada suficientemente. No ha habido, hasta el momento, una teorización adecuada de su naturaleza cooperativa. $\mathrm{Y}$ es que el movimiento de las Ikastolas es un cooperativismo exclusivamente pragmático, ligado a la auto-organización para la prestación 
del servicio educativo y cultural. Esta falta de teorización influye negativamente en su imagen pública (Zelaia, 1997: 92-93).

En nuestra opinión, esta falta de reconocimiento y de teorización ha de ser remediada mediante la investigación universitaria aplicada a este ámbito cooperativo. Dicha teorización cooperativa es un medio necesario para garantizar y fortalecer el potencial social de este movimiento. Por ello, la investigación empírica que proponemos es útil para dicho propósito.

\subsection{El cooperativismo de enseñanza como tercera vía en el sistema educativo}

El cooperativismo de enseñanza se constituye como una tercera vía en los sistemas educativos, entre lo público y lo privado convencional (Fernández Guadaño, 2000: 60-61; Fuentes Viñas y otros, 2002: 51). Se trata de una alternativa empresarial y pedagógica sin ánimo de lucro y de servicio a la sociedad, que surge de la comunidad y es gestionada por todas las partes del proceso, a saber, alumnos y padres, profesores y demás trabajadores, administraciones públicas y empleadores, etc. (Fuentes Viñas, Arturo M. y otros, 2002: 65-66). En este sentido, el cooperativismo de enseñanza es una experiencia de democratización del sistema educativo, de innovaciones pedagógicas (Huedo y Albelda, 2000: 115) y de preservación de las culturas autóctonas (Delcán, 2000: 149).

En consecuencia, la fórmula cooperativa es plenamente adaptable al modelo educativo, dada sus características de neutralidad, de gestión y de participación democrática, autonomía e interés por la comunidad (Fernández Blanco, 2000: 80). Así, se convierte en un medio idóneo para el desarrollo de la educación, tanto en el campo de la enseñanza no reglada, como en la enseñanza reglada y no sólo en la educación infantil, primaria, secundaria, sino también en la educación superior, sea ésta universitaria o de formación profesional (Díaz de Cerio, 2000: 123-124). En definitiva, las cooperativas de enseñanza son un pilar importantísimo dentro de cualquier sistema educativo (Fernández Blanco, 2000: 77).

En lo que a la gestión se refiere, si bien en épocas pasadas las cooperativas de enseńanza se encontraban en un entorno estable y poco agresivo, con cambios predecibles a corto y largo plazo, con baja competitividad y con crecimiento sostenido debido a la alta natalidad, su estado actual se caracteriza por ser un entorno más dinámico y competitivo (Delcán, 2000: 150-154), marcado por la globalización económica, la sociedad de la información (Delcán, 2000: 155; Fernández Guadaño, 2000: 56-57) y los problemas de financiación, debidos en parte a la discrecionalidad de las administraciones públicas (Zelaia, 1997: 84). 
En este contexto complejo y competitivo, la situación a partir del 2000 es de consolidación y éxito empresarial. Pueden considerarse a las cooperativas de enseñanza como empresas con un alto grado de facturación y de afiliación, con una saneada situación patrimonial, una razonable estabilidad en los ingresos, unos precios competitivos que ayuden a cubrir costes y con grandes subvenciones públicas (García-Gutiérrez, 2000: 178).

Como retos de futuro, y ante este nuevo entorno, es necesario impulsar un fuerte incremento de los niveles de eficacia de las organizaciones, mediante una constante adaptación y renovación en los aspectos académicos (como, por ejemplo, el empleo de las nuevas tecnologías) y de gestión, aumentando del mismo modo los niveles de exigencia de calidad (Delcán, 2000: 151; 158-167). Todo ello como medio para la consecución de las metas de las cooperativas de enseñanza: eficiencia, rentabilidad, mayor productividad, innovación, mejora, crecimiento y finalmente, la calidad de la enseñanza (Fuentes Viñas y otros, 2002: 73).

Como podemos observar, estos últimos elementos citados son las variables financieras y no financieras a las que estamos haciendo referencia durante toda nuestra investigación. Mejorar el control y la gestión de estas variables es básico en el cooperativismo de enseñanza.

\subsection{El movimiento cooperativo de las Ikastolas}

La experiencia cooperativa de las Ikastolas es un referente a tener en cuenta, tanto a nivel del propio movimiento cooperativo vasco, como a nivel europeo (Zelaia, 1997: 83). La razón de ser de este movimiento, de su constitución y posterior desarrollo, se encuentra en la crisis que la cultura vasca y el Euskara en particular sufrieron durante el siglo pasado. La imposibilidad por parte del sector público y del sector privado tradicional de hacer frente a esta crisis, propició la constitución de iniciativas, que bajo la fórmula jurídica cooperativa, tuvieron como finalidad impulsar por parte de los padres, una educación enraizada en la cultura vasca (Zelaia 1997: 83; Fernández, 1994).

Según (Gurrutxaga y Unceta, 2010: 111), el movimiento de las ikastolas («lugar para aprender» en euskara), constituyen un modelo único, concretamente, "una realidad educativa, pero sobre todo lingüística aunque también cultural e identitaria, que terminará promoviendo relaciones inéditas entre esas tres dimensiones». Según los autores, la ikastola se presenta como un espacio educativo social-identitario-intersubjetivo por oposición al representado por el modelo público-estatal. 


\subsubsection{LAS IKASTOLAS COMO CENTROS DE ENSEÑANZA DE PARTICIPACIÓN SOCIAL}

Las ikastolas son un experimento de cooperativización de la educación. En este sentido, cabe señalar el tema de la titularidad integral de la cooperativa. Sería el caso de las Ikastolas constituidas como cooperativas de enseñanza mixta o integrales, es decir, como cooperativas de enseñanza en la que comparten titularidad societaria tanto los padres o alumnos, como los trabajadores de la cooperativa. Hablamos del modelo dual del cooperativismo de enseñanza. Este sería el modelo impulsado desde la Experiencia de Mondragón, que a pesar de su éxito e importancia filosófica, no se ha extendido mayoritariamente al resto de experiencias cooperativas de enseñanza, salvo ciertas Ikastolas (Zelaia, 1997: 87).

En relación a esta integración del colectivo de usuarios en la estructura societaria, Imanol Igeregi, primer director de la cooperativa europea Euskal Herriko Ikastolak, afirma que "además de los valores que animan al cooperativismo en igualdad, democracia, responsabilidad, ayuda mutua, solidaridad y equidad, las Cooperativas de Enseñanza tienen un gran potencial para que todos los estamentos que formamos un centro educativo, pero sobre todo dos, familias y profesorado, formen parte conjuntamente, corresponsablemente, de la misma organización. Desde la estructura de la Cooperativa, sobre todo de la Cooperativa «integral», de familias y trabajadores docentes y no docentes, podemos dar un paso que supera las expectativas que nos propone la legislación educativa actual. No sólo podemos participar en la gestión de un centro y tomar parte en algunas decisiones, sino que podemos ser cotitulares de los centros, corresponsables de sus decisiones más importantes. Desde ese punto de vista, más allá de la participación, la Cooperativa puede ser un traje a medida para las necesidades de un centro de enseñanza» (Erkide, 2009: 14).

\subsubsection{LAS IKASTOLAS COMO ORGANIZACIONES DE NATURALEZA NO LUCRATIVA Y DE INTERÉS GENERAL}

Otro aspecto importantísimo en relación a la esencia cooperativa diferenciada de las Ikastolas es su naturaleza no lucrativa y de interés general. Según Zendoia, «la mayoría de nuestros centros tienen calificación de utilidad pública, es decir, no tienen ánimo de lucro (...). Nuestro modelo y nuestro concepto de enseñanza se pueden resumir en una única frase: la enseñanza es un bien público para su gestión social» (Zendoia, 2009).

Enlazando con los conceptos "público» y «social», y tal y como se desprende de la investigación desarrollada por el sociólogo de la Universidad del País Vasco, el doctor Marce Masa, las Ikastolas de identifican completamente 
con la definición que realiza la organización Young Foundation sobre la Innovación Social (Euskaltzaindia y Euskal Herriko Ikastolak, 2010: 314-316), a saber, «las actividades y servicios destinados a satisfacer necesidades sociales, estando desarrolladas y difundidas tales actividades por organizaciones con finalidad exclusivamente social» (Young Foundation, 2006: 11).

Así, las Ikastolas estarían creadas por ciertos colectivos pertenecientes a la sociedad civil, que habiendo detectado ciertas necesidades sociales sin cubrir por los sectores público y privado convencional (concretamente, necesidades educativas ligadas a perspectivas lingüísticas y culturales determinadas), deciden por iniciativa propia realizar las acciones populares pertinentes para la cobertura de dichas necesidades. De esta manera, las Ikastolas han constituido un tercer espacio entre lo público y lo privado, convirtiéndose así en un ejemplo paradigmático de innovación social (Masa, 2010).

\subsubsection{LAS IKASTOLAS COMO ORGANIZACIONES AVANZADAS EN GESTIÓN}

Cabe destacar el peso que la Cultura de la Calidad Total posee en las Ikastolas. Remarcamos el compromiso con la excelencia por parte de las cooperativas de enseñanza asociadas a Agrupación de Cooperativas de Enseñanza de Euskadi. La implementación del modelo EFQM está muy extendido en dichas cooperativas, como instrumento de mejora continua en la gestión. Así mismo, la aplicación del modelo EFQM en las Ikastolas ha sido un revulsivo para la mejora de su gestión integral, desde principios de la década del 2000 hasta la actualidad (Euskaltzaindia e Ikastolen Elkartea, 2010).

\subsubsection{LAS IKASTOLAS COMO MOVIMIENTO SOCIAL}

Las Ikastolas se pueden definir como un «movimiento popular», que comienza su andadura en la clandestinidad, en pisos de particulares y con un número muy reducido de alumnos, y que logra su expansión mediante la aportación y dedicación común de los padres y madres, profesorado y de las más diversas e imaginativas formas de participación popular, siendo la autogestión y la autofinanciación un común denominador de este movimiento social incipiente (Basurto, 1989: 139-145).

Según Masa (2010), es habitual hallar la consideración de «movimiento» en los análisis de las Ikastolas (Arpal y otros, 1982, 45; Basurto 1989, 139; Onaindia 1994, 11; Fernández 1994, 99; Dávila Balsera 2003, 33). Según el sociologo de la UPV/EHU, el término «movimiento» hace referencia a todas aquellas prácticas sociales que surgen de un ámbito localizado fuera de las lógicas de lo público y lo privado, es decir, un escenario social o "popular", en el que se encuentran un conjunto de prácticas y estrategias que se desarrollan al margen de las acciones públicas y privadas, 
pero que tienen un importante protagonismo en la estructuración de la vida cotidiana.

\subsubsection{ObSERVANCIA DEL PRINCIPIO «COOPERACIÓN ENTRE COOPERATIVAS»}

Es en su característica interregional donde las ikastolas desarrollan el principio de "Cooperación entre cooperativas», materializado en el asociacionismo cooperativo: en el 2009 se constituyó, por parte de las distintas federaciones de Ikastolas, la denominada Euskal Herriko Ikastola, una cooperativa de segundo grado formada según el estatuto de cooperativa europea e integrada por 110 cooperativas de las distintas federaciones de Ikastolas. Su labor viene a sustituir el papel que históricamente venía realizando la Confederación de Ikastolas (Ikastolen Konfederazioa, 2009: 11-14), pero integrando en una única figura jurídica cooperativa a la totalidad de ikastolas, de manera que las ikastolas participan, por vez primera y de forma directa, en una supra-estructura cooperativa, sin tener que depender así de las respectivas federaciones (Erkide, 2009: 20-21; Hik Hasi, 2010: 18-19).

\subsubsection{CONCLUSIÓN: UN OBJETO DE INVESTIGACIÓN DE GRAN INTERÉS}

Una cooperativa europea, formada por 110 ikastolas, 4.500 profesores, 500 trabajadores no docentes y 56.000 alumnos, con una filosofía de participación e integración de toda la comunidad educativa (un total de 61.110 personas), sin ánimo de lucro y de interés general, con orientación hacia la innovación social y hacia la gestión avanzada de sus cooperativas, constituidas como grupo empresarial y mas allá, como movimiento social de transformación pedagógica y de fortalecimiento del Euskara y la cultura vasca. Tenemos entre manos una gran oportunidad para generalizar en dicho movimiento las medidas de mejora que planteamos diseñar.

Por todo ello, y teniendo en cuenta su déficit de teorización como experiencia cooperativa, el movimiento cooperativo de las ikastolas es un objeto de investigación de gran interés para el trabajo que estamos proponiendo.

\section{Parte empírica: metodología aplicada y fases de nuestro estudio}

\subsection{Perspectiva utilizadas}

Tras delimitar conceptualmente el problema (la dualidad socioeconómica de las EESS y la necesidad de realizar una gestión equilibrada de esa 
dualidad) y proponer las herramientas para solucionarlo (los sistemas de indicadores de gestión de carácter multidimensional), nuestra intención es realizar una investigación empírica para profundizar tanto en el mismo problema de gestión como en los instrumentos propuestos. Para ello, hemos diseñado un trabajo de campo con las siguientes perspectivas o características:

- Naturaleza inductiva: no hemos optado por una investigación hipotética-deductiva, es decir, no planteamos una hipótesis para luego tratar de contrastarla en la realidad. Nuestra intención es analizar la realidad de las organizaciones e inducir de dicha observación unas ideas clave que nos ayuden a mejorar dicha realidad.

-Estudio de un caso múltiple: queremos que nuestra investigación sea de un interés práctico importante, por lo que optamos por tener una conexión directa con la realidad empresarial de las EESS. Para ello, hemos elegido a un grupo de EESS, constituído formalmente y coordinado en el plano organizativo. La razón de esta elección estriba en que el estudio de un grupo formado por un centenar de cooperativas facilita que el análisis y las propuestas de mejoras sean homogéneas y a su vez, de un impacto muy importante en el seno del mismo grupo. Analizaremos el caso de las Ikastolas, unas cooperativas de enseñanza, que con filosofía participativa y con talante de transformación pedagógica, se constituyen como movimiento social gracias a la labor de fomento que realizan en relación a la cultura y lengua vascas. Dada la importancia "cooperativa» de este grupo de EESS, en el apartado 5. ${ }^{\circ}$ haremos un breve repaso de las características del movimiento cooperativo de las Ikastolas.

- Naturaleza descriptiva, valorativa y prescriptiva: el estudio del caso propuesto se realizará mediante una secuencia de fases concreta, unas de ellas de carácter descriptivo y valorativo (pretendemos analizar de forma profunda la realidad de las EESS) y en base a estas fases preliminares, una fase final de carácter propositivo, donde propondremos medidas de mejora concretas.

En función de estas perspectivas, hemos optado por un enfoque metodológico triangular, es decir, por una triangulación metodológica en la que complementamos técnicas cualitativas y cuantitativas: la combinación de metodologías cuantitativas y cualitativas enriquece nuestra investigación, ya que si bien las técnicas cuantitativas nos darán una fotografía general de la realidad empresarial a analizar, mediante las técnicas cualitativas profundizaremos en el caso elegido. 


\subsection{Fases}

La investigación empírica la hemos dividido en una serie de fases, en las que combinamos metodologías cuantitativas y cualitativas para su desarrollo. La secuencia de fases sería la siguiente:

i. Fase exploratoria, mediante metodología cualitativa (entrevista en profundidad): antes de entrar de lleno en la parte empírica de nuestro trabajo de investigación, decidimos realizar una entrevista en profundidad al gerente de una Ikastola a la que el equipo de investigación tenía «facil» acceso. Al tratarse de una persona cualificada en la temática elegida (gestión de la calidad y gestión estratégica), esta fase nos ayuda a tener una fotografía inicial de la situación de los sistemas de informacion para la gestion del conjunto de las Ikastolas y confirmar el psoible interés de las Ikastolas en relación al problema que queremos analizar. Por otro lado, utilizamos este primer contacto para acordar la siguiente fase con el moviento de las ikastolas.

ii. Fase exploratoria cualitativa (entrevista en profundidad) para el diseño y puesta en marcha de la fase cuantitativa (encuestas): gracias al primer contacto de la fase anterior, pudimos acordar formalmente con representantes oficiales del movimiento de las Ikastolas (mediante convenio firmado por Euskal Herriko Ikastolak y el Instituto GEZKI de la UPV/EHU) las siguientes fases de la investigación. En concreto, fijamos el contenido del modelo de encuesta que enviaríamos a las ikastolas asociadas y fijamos un cronograma para las siguientes fases. Queda totalmente verificado el interés de las ikastolas por la investigación que les hemos propuesto.

iii. Fase descriptiva-valorativa de carácter cuantitativa (encuestas): la encuesta consta de dos partes. La primera de ellas, totalmente descriptiva, en la que además de recoger información sobre las características de cada Ikastola (dimensión, localización, estructura...), analizamos también los sistemas de información para la gestión que utilizan actualmente (contabilidad financiera, de costes, presupuestos, gestión de la calidad y gestión estratégica). La segunda parte de la encuesta trata de que los gerentes de las Ikastolas elijan de entre una serie de 60 indicadores, los más importantes para el control de su gestión. Los indicadores propuestos están divididos entre las diferentes perspectivas del Cuadro de Mando Integral adaptado a las características de las EESS/Ikastolas: alumnos, madres/padres, comunidad, economía, procesos y formación/mejora. Por lo tanto, esta fase también tiene un componente propositivo. Los resultados de las encuestas serán compartidos y valorados conjuntamente con los responsables de Euskal Herriko Ikastolak. 
iv. Fase descriptiva-valorativa de carácter cualitativa (entrevistas en profundidad): una vez analizados los resultados de las encuestas con los responsables de las Ikastolas, acordaremos con dichos responsables las Ikastolas a las que se les hará entrevistas personalizadas, profundizando en los contenidos analizados en la encuesta y sobre todo, valorando nuestra propuesta de indicadores. Tal y como señalábamos en el caso de las encuestas, esta fase también tiene ya un componente propositivo.

v. Técnica de inmersión: desde junio del 2014, Unai del Burgo García es miembro del Consejo Rector de una Ikastola que se encuentra en la actualidad en un proceso de reflexión estratégica. Si bien esta fase tiene una finalidad descriptiva y valorativa de la situación de los sistemas de información para la gestión, no se descarta que pueda tener una función propositiva en la que se implementen medidas de mejora e incluso el sistema de indicadores propuesto en esta investigación para las Ikastolas.

vi. Fase propositiva: ésta sería la última fase de la investigación. Tras analizar los resultados de las encuestas y de las entrevistas realizadas, presentaremos a las ikastolas un sistema propio de indicadores de gestión, además de mejoras o directrices generales en sus restantes sistemas de información para la gestión empresarial.

Las metodologías empleadas garantizan, en nuestra opinión, un conocimiento profundo de la realidad de las EESS que queremos analizar y sobre todo, capacidad de influencia para implementar las medidas de mejora a proponer.

\section{Fases exploratorias: el interés por parte de las ikastolas de desarrollar un sistema propio de indicadores de gestión}

En este apartado, vamos a exponer los resultados obtenidos de las dos primeras fases de la investigación empírica (ver apartado 4.2). Concretamente, nos referimos a las fases exploratorias de dicha investigación:

\subsection{Fase exploratoria, mediante metodología cualitativa (entrevista en profundidad)}

La finalidad de esta fase es conocer mejor nuestro objeto de estudio y confirmar el interés práctico de la investigación que proponemos. Para ello, hemos realizado el estudio de un caso mediante una entrevista en pro- 
fundidad de 2 horas de duración (17.30-19.30), con un cuestionario predeterminado formado por preguntas abiertas y cerradas, de manera que si bien no perdemos en ningún momento el hilo argumental de la entrevista, no bloqueamos las aportaciones del entrevistado.

La entrevista se realizó el 4 de octubre del 2017 al gerente o director de una Ikastola a la que el equipo investigador tenia fácil acceso por cercanía personal, lo que facilita la realización de este experimento exploratorio. La identidad de la ikastola es confidencial, a petición del propio director, ya que en la entrevista realizada aparecen muchos aspectos críticos para la Ikastola que deben ser corregidos y mejorados.

A continuación expondremos brevemente los resultados más importantes que hemos recopilado de la entrevista en profundidad realizada.

\subsubsection{Descripción general de la IKastola}

La ikastola en cuestión tiene un largo recorrido: se constituyó en 1977, desde el primer momento bajo la fórmula jurídica de cooperativa. Por lo tanto, es una organización con una gran experiencia en el sector, lo que puede facilitar «a priori» que ya tenga un bagaje importante en temas de gestión.

Se trata de una cooperativa de socios usuarios, es decir, de madres y padres. Los trabajadores no son socios cooperativistas. El director trató de proponer la transformación de la cooperativa en una cooperativa integral donde los trabajadores también fuesen socios cooperativistas, pero el Consejo Rector no aceptó dicha propuesta.

En cuanto a su dimensión, opinamos que posee un tamaño adecuado para poder diseñar y aplicar instrumentos avanzados en gestión: 1.157 alumnos, 900 familias y 87 trabajadores. Entre los trabajadores, 75 profesores y 12 trabajadores no docentes. La estructura de la plantilla de trabajadores no docentes es adecuada para realizar una coordinación apropiada de la entidad: un director (labores de gestión general y de coordinación pedagógica); un administrador (responsable de la gestión económico-financiera) y un auxiliar administrativo como ayudante; otros 9 trabajadores para diferentes funciones (atención al público, coordinación de actividades extraescolares, ayuda pedagógica, responsable de las instalaciones deportivas, etc.). Destacamos que en el ámbito administrativo y económico-financiero, la Ikastola cuenta con dos profesionales cualificados, por lo que las posibilidades de implementar herramientas de contabilidad de gestión es elevada.

Económicamente, la Ikastola tiene un presupuesto anual de unos 6 millones de euros. Según el director, la situación económico-financiera de la Ikastola es estable, bien desde el punto de vista del nivel de endeudamiento, bien desde el punto de vista de la liquidez. 
La estructura de la Ikastola es la siguiente: además de los órganos sociales de las cooperativas (asamblea general, consejo rector, comisión de vigilancia), existe la comisión de padres (se reúnen dos veces al año) y el consejo de dirección. Este órgano está formado por el director, los jefes de estudio (educación infantil, primaria, secundaria y bachiller) y el administrador. Además del órgano de dirección, el director ha formado un grupo de apoyo denominado "grupo de trabajo permanente», que se reúne una vez a la semana, para tratar temas de gestión, formado por el propio director, el presidente, el administrador y un miembro del consejo rector.

\subsubsection{Sistemas de contabilidad}

La gestión económico-financiera se desarrolla por dos personas, el administrador y su ayudante. Como hemos apuntado, la Ikastola tiene personal suficiente para implementar herramientas avanzadas en contabilidad de gestión. No obstante, a día de hoy, hay puntos importantes por mejorar.

Los datos contables son transmitidos al Consejo Rector una vez al ańo, en forma de cuentas anuales, es decir, balance y cuenta de resultados (no se les transmite información generada por la contabilidad de costes).

En el "grupo de trabajo permanente» si se hace un seguimiento a la situación económico-financiera de la cooperativa, pero no de un modo sistemático: no hay un modelo concreto ni una frecuencia concreta. Esta información contable si se clasifica por "programas» (pedagogía, comedor, transporte, actividades extra-escolares), no obstante, la actividad pedagógica no se analiza por ciclos, sino en su conjunto.

En cuanto al presupuesto, este abarca el curso lectivo (es decir, el ciclo contable de la Ikastola). Su diseño se realiza en mayo y en un plazo de un mes se presenta a la asamblea general. La intención de la dirección es que los presupuestos sean participativos y que se instaure en la organización una "cultura de la previsión y de la evaluación explicita», donde cada programa tenga su presupuesto anual. No obstante, esta visión no está aún sistematizada, por lo que el proceso presupuestario es vertical, y no participativo.

\subsubsection{Sistemas DE GeSTIÓN DE LA CALIDAD}

La ikastola lleva 8 años desarrollando sistemas de gestión de calidad, contando para ello con un consultor externo. Gracias a este consultor, se han descrito todos los procesos de la Ikastola. Pero la gestión de la calidad ha ido más allá de la descripción de procesos, por lo que la Ikastola ha implementado modelos de gestión de la calidad total. A la pregunta de si han 
optado por el modelo EFQM, el director afirma que dicho modelo crea «una burocracia demencial», por lo que es ingestionable, desde su punto de vista. Por ello, han optado por el Modelo de Gestión Avanzada de Euskalit, la agencia vasca para la calidad total, en su opinión, un modelo mucho más simple y ágil para la gestión de la calidad total. Para el control de dicho modelo, la ikastola utiliza una batería de indicadores mucho más sencillo que lo propuesto por el modelo EFQM.

Otro aspecto importante en este ámbito de la gestión, es el hecho de que la ikastola pertenece a un grupo de ikastolas dentro del mismo movimiento, que han creado el «seminario de gestión avanzada». Se trata de ikastolas que tienen la intención y la voluntad de mejorar sus sistemas de información para la gestión. En dicho seminario se debaten y se acuerdan medidas conjuntas para mejorar dichos sistemas de gestión. El seminario está compuesto por 7 ikastolas y se reúnen una vez cada tres meses aproximadamente.

\subsubsection{Gestión estratégica}

La ikastola ha estado inmersa en el curso 2016/2017 en un proceso de reflexión estratégica, es decir, la ikastola pretende fijar su rumbo estratégico, que quiere ser y a donde quiere ir. Se han debatido multitud de variables, como el tamańo, tipo de educación, criterios para la convivencia, perfil de salida de los estudiantes, etc. Para dirigir este proceso, la ikastola ha contado con un consultor externo, con el resultado de que se han identificado las perspectivas estratégicas esenciales para realizar su recorrido estratégico: cooperativismo, pedagogía, gestión, participación de las familias, euskara y comunicación.

A partir de aquí, la labor del consultor ha terminado, y la ikastola se centra en el curso 2017/2018 en profundizar dicho proceso y en gestionarlo, de manera que operativiza cada perspectiva de la siguiente manera: objetivo anual para cada perspectiva, acciones concretas, diseńo de indicadores para cada acción, control de desviaciones y medidas de mejora. En definitiva, la ikastola se ha puesto como objetivo diseñar un sistema de indicadores de gestión de carácter multidimensional, que le ayude a gestionar las perspectivas que se han fijado. El responsable de dicho sistema es el director. En sus manos recae la labor de diseñarlo e implementarlo.

En el momento de realizar la entrevista, el sistema de indicadores estaba aún sin diseñar. No obstante, el director tenía en mente las características generales de dicho sistema: flexible, simple y fácil de gestionar. En su opinión, no se pueden gestionar más de 30 indicadores. Por otro lado, la comparación de resultados sería muy provechoso para la ikastola, como para el movimiento de ikastolas en general. 
No obstante, el director es consciente de las limitaciones de los indicadores para gestionar ciertas variables difícilmente cuantificables, como el perfil de salida del alumnado. En este sentido, la intuición y los juicios subjetivos son clave.

\subsubsection{Conclusiones generales y pasos a Seguir}

La finalidad de esta primera fase exploratoria era identificar los elementos que señalábamos en el marco teórico, describiendo en la práctica estos elementos, valorándolos y proponiendo elementos de mejora. En este sentido, extraemos de la observación realizada las siguientes conclusiones:

i. Aspectos generales de la ikastola: la dimensión y la estructura de la organización influyen en su necesidad y capacidad para diseñar y utilizar sistemas avanzados de información para la gestión empresarial. En nuestra opinión, la ikastola analizada tiene capacidad y necesidades para diseñar y utilizar dichas herramientas avanzadas, más aún cuando el director tiene la intención expresa de diseñar un sistema de indicadores de gestión.

ii. Sistemas de contabilidad: la ikastola tiene intención de mejorar sus sistemas de información contable, en concreto, de formalizar y sistematizar completamente su proceso presupuestario, convirtiendo su sistema de presupuestos "vertical» en uno "participativo", clasificándolo por "programas», en concreto, por ciclos o etapas educativas y por servicios complementarios (comedor, transporte, extraescolares). Por otro lado, la contabilidad de costes también es un ámbito a desarrollar: una vez diseńado el presupuesto "por programas", será necesario calcular las desviaciones y proponer las medidas de mejora adecuadas. Dicho control presupuestario (contabilidad de costes) deberá realizarse como mínimo cada tres meses.

iii. Sistemas de gestión de la calidad: la Ikastola ha ido más allá de la formalización de su información contable y ha implementado modelos de gestión de la calidad total, como es el modelo de Euskalit. De este modo, la Ikastola gestiona mediante indicadores los 6 elementos del modelo (estrategia, clientes, personas, comunidad, innovación y resultados). Nuestra duda es si realmente este modelo es útil en la práctica para la gestión de la Ikastola y si es necesario un modelo más simple relacionado con la gestión estratégica de la Ikastola.

iv. Gestión estratégica: este punto es clave. Se confirma la importancia de la investigación que proponemos. La ikastola quiere diseñar un sistema de indicadores multidimensionales que le permita controlar 
su estrategia anualmente. $\mathrm{Y}$ dentro de esas variables multidimensionales está el cooperativismo. Aún no se ha diseñado dicho sistema de indicadores, por lo que éste es el gran reto de la ikastola en relación a sus sistemas de información para la gestión.

Mediante la persona entrevistada en esta primera fase, pudimos contactar con el «seminario de gestión avanzada» de las Ikastolas. Realizamos una propuesta de acuerdo o convenio para la realización conjunta del proyecto de investigación que presentamos en este documento. Dicha propuesta fue defendida por el director de la Ikastola entrevistado en la primera fase. Los integrantes del «seminario de gestión avanzada» mostraron su interés en dicha investigación y en los elementos de mejora que pueden derivarse de la propia investigación. En conclusión, abordamos la segunda fase de la investigación empírica, acordando una reunión/entrevista con la coordinadora del seminario Amaia Gutierrez Urutxurtu, responsable de calidad de la Ikastola Txintxirri de Elorrio (Bizkaia), para diseñar las siguientes fases de la investigación y realizar una propuesta firma de acuerdo entre GEZKI (UPV/EHU) y la agrupación de Ikastolas.

\subsection{Fase exploratoria cualitativa (entrevista en profundidad) para el diseño y puesta en marcha de la fase cuantitativa (encuestas)}

La entrevista se realizó el 23 de abril del 2018, con un representante de Ikastolen Elkartea. La persona entrevistada es coordinadora de un grupo específico de trabajo formado dentro de la propia federación de Ikastolas: se trata de un «seminario» que reúne a un grupo reducido de Ikastolas interesadas en temas de gestión de la calidad total y en modelos avanzados de gestión.

La estructura de la entrevista era la siguiente: tras realizar una breve exposición de nuestro proyecto de investigación, le proponemos al entrevistado que ratifique el interés de Ikastolen Elkartea en nuestro estudio, para a continuación recoger sus aportaciones sobre las siguientes fases de la investigación y sobre la estructura de la encuesta que le proponíamos. Tras dos horas de reunión, recogemos sus aportaciones, que son plasmadas en una propuesta de acuerdo donde se describen las siguientes fases de la investigación (ver apartado 6.2. de este artículo) y la encuesta que utilizaremos en la tercera fase de la parte empírica de nuestro proyecto.

Con todo este material, se transmite la propuesta (acuerdo GEZKIIkastolas y encuesta) al director de Euskal Herriko Ikastolak, que confirma su interés por el proyecto, de manera que la tercera fase «descriptiva-valorativa de carácter cuantitativa» se pone en marcha realizando una distribu- 
ción de las encuestas vía telemática a las ikastolas en dos envíos, una primera del 1 al 15 de junio y una segunda del 1 al 15 de julio. Esta tercera fase (estudio de los resultados), a día de hoy, sigue en marcha.

\section{Conclusiones}

En el presente documento hemos expuesto los puntos claves de nuestro proyecto de investigación. El marco conceptual se centra en las características especiales que poseen las entidades de economía social y solidaria en el ámbito de la gestión. La naturaleza empresarial o económica de estas entidades confluye con su naturaleza social. Esta dualidad socioeconómica tiene que ser gestionada de manera equilibrada y para ello, proponemos la utilización de nuevas herramientas de contabilidad de gestión, como los sistemas de indicadores gestión de carácter integral (compuestos por indicadores financieros y no financieros), entre ellos, destaca el Cuadro de Mando Integral o Balanced Scorecard. No obstante, estas herramientas tienen que estar a las entidades que las van a utilizar.

Dado que nuestra intención es la aplicación práctica de nuestras propuestas, desde el Instituto de Derecho Cooperativo y Economía Social de la Universidad del País Vasco (GEZKI), hemos diseñado conjuntamente con la agrupación de Ikastolas (Euskal Herriko Ikastolak, un movimiento de cooperativas de enseńanza referente en Euskadi y Navarra), una investigación empírica que, complementando metodologías cuantitativas y cualitativas, describa la situación actual de los sistemas de información para la gestión del conjunto de las ikastolas y ayude a proponer mejoras en los mismos, siendo el resultado final el diseño de un sistema de indicadores para la gestión integral para el movimiento cooperativo de las ikastolas.

La investigación empírica acaba de comenzar, pero las fases exploratorias preliminares nos muestran que hay aspectos importantes para mejorar en los sistemas de información para la gestión en el seno de las ikastolas. Ademas, confirmamos la existencia de un interés inequívoco y expreso de aplicar en dicho movimiento un sistema de indicadores que facilite la gestión equilibrada de las ikastolas que lo integran.

Como conclusión final, debemos señalar que cada tipo de organización debe de contar con sus propios sistemas de información para la gestión, es decir, debe de contar con instrumentos de evaluación de la gestión «hechos a medida». Tenemos el convencimiento de que la metodología que estamos actualmente desarrollando puede aplicarse en un futuro a otros grupos y movimientos pertenecientes a la Economía Social y Solidaria, como herramienta para garantizar su dualidad socio-económica y su gestión equilibrada. 


\section{Referencias}

AECA (2001): La Contabilidad de Gestión en las Entidades sin fines de Lucro, Comisión de Contabilidad de Gestión, Documento n. ${ }^{\circ} 24$, Madril.

AECA (2002): Indicadores para la gestión empresarial, Comisión de Contabilidad de Gestión, Documento n. ${ }^{\circ}$ 17, Madril.

AECA, (2003 $)$ : El marco de la contabilidad de gestión, Comisión de Contabilidad de Gestión, Documento n. ${ }^{\circ}$, Madril.

AECA (2003 ${ }^{\text {b }}$ : La contabilidad de gestión como instrumento de control (4. ed.), Comisión de Contabilidad de Gestión, Documento n. ${ }^{\circ}$ 2, Madril.

Agirre, A. (2001): «Los principios cooperativos atractores de la gestión eficiente: su medición. Aplicación al caso de Mondragón Corporación Cooperativa», Ciriec-España, 39. zenbakia, páginas 93-113.

Aguirre, M.S.; Albizu, E.; Landeta, J. y Charterina, J. (2006): «Análisis empírico descriptivo de las prácticas y técnicas de gestión de las empresas vascas», Ekonomiaz: revista vasca de economía, 62, Ogasun eta Herri Administrazio Saila, Eusko Jaurlaritza.

Alvarez, J. y Blanco, F. (2001): «Contabilidad de Dirección Estratégica para la Gestión Empresarial», Técnica Contable, 53. bol., 636. zk.

Amat, J.M. (2003): Control de Gestión. Una perspectiva de dirección (6o edición), Gestión 2000, Bartzelona.

Amat, O. y Soldevila, P. (1999): «La aplicación del Cuadro de Mando Integral. Un ejemplo en la Unidad de Relaciones Internacionales de una Universidad Pública», Auditoría pública: revista de los Organos Autónomos de Control Externo, 17. zenbakia, 40-45. orrialdea.

Arpal, J.; Asua, B. y Dávila, P. (1982): Educación y Sociedad en el País Vasco, Editorial Txertoa, Donostia-San Sebastián, citado en (Masa, 2010).

Azkue, I. y Zubiaur, G. (1996): Kontabilitate Plan Orokorra, EHUko argitalpen zerbitzua, Leioa.

Barea, José y Pulido, Antonio (2001): «El sector de instituciones sin fines de lucro en España», CIRIEC-España, Revista de Economía Pública, Social y Cooperativa, n. ${ }^{\circ}$ 37, págs. 35-49.

Bellostas, A., Brusca, I. y Moneva, J. (2008): «Utilidad Financiera para la Gestión de las Entidades Privadas No Lucrativas», Revista de Contabilidad, ASEPUC, volumen 9, n. ${ }^{\circ}$ 18, pág. 87-109.

Blanco, F. (2008): La Contabilidad de Costes y Analitica de Gestión para las decisiones estratégicas, Ediciones Deusto, Barcelona.

Borzaga, Carlo eta Santuari, Alceste (2003): «New Trends in the Non-Profit Sector in Europe: The emergence of social entrepreneurship", The Non-Profit Sector in a Changing Economy, OECD, Paris.

Cabaleiro, V. y Fernández-Feióo, B. (1997): «Tendencias actuales de la Contabilidad Directiva y su reflejo en los principios y valores cooperativos", Técnica Contable, volumen 49, n. ${ }^{\circ}$ 587, pág. 757-766. 
Chen, S. (2009): «Establishment and application of performance measure indicators for universities», TQM Journal, vol. 21, n. ${ }^{\circ} 3$.

Cid, M. (2005): «Kooperatiben kudeaketa orekatu baten bila: The Blended Scorecard», Kooperatiben enpresa-ekonomia, Mondragon Unibertsitatea, Arrasate, pág. 135-150.

Dávila Balsera, P. (2003): Enseñanza y educación en el País Vasco contemporáneo. Editorial, Erein, Donostia-San Sebastián, citado en (Masa, 2010).

Dahlgaard-Park, S.M. (2008): «Reviewing the European excellence model from a management control view». The TQM Journal, vol. 20, n. ${ }^{\circ}$ 2, Emerald Group Publishing Limited.

Del Burgo, U. y Malles, E. (2010): Los sistemas de información contable en la gestión universitaria. Revista de dirección y administración de empresas = Enpresen zuzendaritza eta administraziorako aldizkaria, n. ${ }^{\circ}$ 17, 119-140.

Del Burgo, U. (2013): «El movimiento cooperativo de las ikastolas: su revisión conceptual desde la perspectiva de las empresas sociales». Revista vasca de economía social $=$ Gizarte ekonomiaren euskal aldizkaria, GEZKI (UPV/EHU), n. ${ }^{\circ}$ 10, 71-96.

Del Burgo, U. y Luengo, M. (2013): «Hezkuntza-erakundeen kudeaketa orekatua EFQM ereduan oinarritutako Balanced Scorecard akademikoa.» Uztaro giza eta gizarte-zientzien aldizkaria, n. ${ }^{\circ}$ 85, 5-29.

Del Burgo, U., Bakaikoa, B., Luengo, M. y Malles, E. (2014): «Ekonomia sozial eta solidarioko erakundeen kudeaketa krisi garaian: oreka ekonomiko-finantzario eta soziala ahalbideratzeko lanabesak». Revista vasca de economía social = Gizarte ekonomiaren euskal aldizkaria, n. ${ }^{\circ}$ extra 0, 235-260.

Delcán Zamudio, Benet (2000): «Reflexiones sobre las claves de gestión futuras de las cooperativas de enseñanza: calidad, mejora continua y servicio como base de la excelencia educativa», REVESCO Revista de Estudios Cooperativos, n. ${ }^{\circ} 71$, Madrid, págs. 149-170.

Díaz de Cerio, Abilio (2000): «Experiencias educativas en la formación profesional», REVESCO Revista de Estudios Cooperativos, n.o 71, Madrid, págs. 123-128.

Druker, P.F. (1990): Managing the non-profit organization: principles and practices, Harper Business, New York, en (CHEN y otros, 2006).

Durden, C. (2008): "Towards a socially responsible management control system», Accounting, Auditing \& Accountability Journal, volumen 21, n. o 5, pág. 671-694.

ERKIDE (2009): «La Cooperativa puede ser un traje a medida para un centro de enseńanza», Koop Aldizkaria, n.o 38, Euskadiko Lan Elkartuko Kooperatiben Federazioa/Federación de Cooperativas de Trabajo Asociado de Euskadi, Vitoria-Gasteiz, págs. 14-16.

Esther, I. (2003): «El paradigma de calidad reformada en el servicio público universitario", Revista iberoamericana de contabilidad de gestión, 2.

Euskaltzaindia y Euskal Herriko Ikastolak (2010): Ikastola mugimendua. Dabilen herria. Ikastola eredua 1960-2010, Jagon Saila, Euskaltzaindia, Bilbao.

Fernández, I. (1994): Oroimenaren hitza. Ikastolen historia 1960-1975, Udako Euskal Unibertsitatea, Bilbao. 
Fernández Blanco, Fernando (2000): «Realidad actual y perspectivas de las cooperativas de enseńanza», Revesco-Revista de Estudios Cooperativos, n.o 71, Madrid, págs. 77-82.

Fernández Guadaño, Josefina (2000): «La realidad actual de las sociedades cooperativas en la educación», Revesco-Revista de Estudios Cooperativos, n. ${ }^{\circ}$ 70, Madrid, págs. 55-76.

Fuentes Viñas, Arturo M. y otros (2002): «Las cooperativas de enseñanza como tercera vía dentro de nuestro sistema educativo: las cooperativas de trabajo asociado. Percepciones de sus directivas», Enseñanza: Anuario interuniversitario de didáctica, n. ${ }^{\circ}$ 20, págs. 51-84.

García Echeverria, S. (1981): "Responsabilidad Societaria y Estrategia Empresarial: Balance Social», Working Paper, 62. zenbakia, Serie Azul, Universidad de Alcalá de Henares, Madrid, pág. 31, en (MUGARRA, 1995: 12).

García-Gutierrez Fernández, Carlos (2000): «La intercooperación de las sociedades cooperativas en la actividad de la educación», Revesco-Revista de Estudios Cooperativos, n. ${ }^{\circ}$ 70, Madrid, págs. 173-196.

Gurrutxaga, A. y Unceta, A. (2010): «La función distributiva de la educa ción: un análisis aplicado al País vasco» Política y Sociedad, vol. 47, n. ${ }^{\circ}$ 2, págs. 103-120.

Heras, I. (2004): Enpresaren ekonomia eta zuzendaritza: teoria eta praktika, Udako Euskal Unibertsitatea, Bilbo.

Hik Hasi (2010): "Abel Ariznabarretari eta Imanol Igeregiri elkarrizketa», n. ${ }^{\circ}$ 146, marzo de 2010, Hik Hasi Aldizkaria, Donostia-San Sebastián, págs. 16-23.

Huedo Berenguer, Julia y Albelda Randis, Laura (2000): «Experiencias cooperativas en los distintos niveles del sistema educativo", Revesco-Revista de Estudios Cooperativos, n. ${ }^{\circ}$ 70, págs. 115-122.

Ikastolen Konfederazioa (2009): «Euskal Herriko Ikastolak. Ikastolen kooperatiba europearra egituratzen ari da», Ikastola aldizkaria, n. ${ }^{\circ} 175$, págs. 11-14.

Kaplan, R.S. y Norton, P. (1996): The Balanced Scorecard: translating strategy into action, Harvard Bussiness School Press, Harvard College.

Luengo, M.J. (2009): Componentes del valor de los intangibles y formación de capital relacional en espacios regionales, tesis doctoral, Finantza-Ekonomia II Departamentua (Enpresen Antolakuntza), Ekonomia eta Enpresa Zientzien Fakultatea, Universidad del País Vasco/Euskal Herriko Unibertsitatea (UPV/EHU).

Masa, M. (2010): Las Ikastolas como un fenómeno de innovación social: estudio de caso, Dpto. Sociología 2, Universidad del País Vasco (UPV/EHU), Bilbao (inédito).

Monzón, J.L. (2006): «Economía Social y fronteras afines: fronteras borrosas y ambigüedades conceptuales del Tercer Sector», CIRIEC-España, Revista de Economía Pública, Social y Cooperativa, volumen 56, págs. 9-24.

Mugarra, A. (1995): Balance Social en Cooperativas, Tesis doctoral en micro-fichas, Universidad de Deusto, Bilbao.

Mugarra, A. (1998): «Proyecto Balance de Identidad Cooperativa», Anuario de Estudios Cooperativos, Instituto de Estudios Cooperativos, Universidad de Deusto, Bilbao, pág. 301-390. 
Mugarra, A. (2000): «Planteamiento de un Modelo de Balance Cooperativo: Aplicación a Mondragón Corporación Cooperativa», Anuario de Estudios Cooperativos, Instituto de Estudios Cooperativos, Universidad de Deusto, Bilbao, págs. 221-276.

Mugarra, A. (2000): «Planteamiento de un Modelo de Balance Cooperativo: Aplicación a Mondragón Corporación Cooperativa", Anuario de Estudios Cooperativos, Instituto de Estudios Cooperativos, Universidad de Deusto, Bilbao, págs. 221-276.

Mugarra, A. (2002): «El Balance Social para las Cooperativas de Iniciativa Social», Temas de Economía Social, GEZKI (EHU), Donostia, 61-87. orr.

Mugarra, A. (2005a): «Memoria de sostenibilidad: una propuesta adaptada para las cooperativas de enseñanza en el País Vasco», CIRIEC-España, Revista de la Economía Pública, Social y Cooperativa, n.o 53, págs. 333-349.

Mugarra, A. (2005b): «Gizarte Erantzunkizun Kooperatiboa eta Balantze Soziala Kooperatibetan", Kooperatiben enpresa-ekonomia, Mondragon Unibertsitatea, Arrasate, págs. 283-307.

Mugarra, A. y Enciso, M. (1997): «Principio Cooperativo de Gestión Democrática: Análisis de las Garantías recogidas en la legislación, en los Estatutos e Indicadores Evaluativos para una Cooperativa de Mondragón», Anuario de Estudios Cooperativos, Instituto de Estudios Cooperativos, Universidad de Deusto.

Onaindia, M. (1994): "La Escuela Pública Vasca y la construcción nacional», Cuadernos de Alzate, n. ${ }^{\circ}$ 20, págs. 9-63, citado en (Masa, 2010).

Parker, (2000): «Divisional perfomance measurement: beyond an exclusive profit test», Acounting and Business Research, págs. 309-319, en (Soldevilla 2000: 95).

Sajardo, A. y Chaves, R. (2006): «Balance y tendencias en la investigación sobre Tercer Sector no lucrativo. Especial referencia al caso español», CIRIEC-España, Revista de Economía Pública, Social y Cooperativa, n. ${ }^{\circ}$ 56, pág. 87-116.

Salomon, L. y Anheier, H.K. (1992): «In search of the non profit sector I: the question of definitions», Voluntas, n. ${ }^{\circ}$ 2, 1992, pp. 125-151, en (Barea y Pulido, 2001).

Santos, M. eta Fidalgo, E. (2004): «Un análisis de flexibilidad del Cuadro de mando Integral (CMI) en su adaptación a la naturaleza de las organizaciones», Revista iberoamericana de contabilidad de gestión, n. ${ }^{4}$, págs. 85-116.

Soldevila, P. (2000): El Control de Gestión en las Organizaciones no lucrativas: el caso de los colegios profesionales de España, tesis doctoral, Barcelona.

Soldevila, P. y Amat, O. (2002): "Contabilidad de gestión en las entidades sin ánimo de lucro", AECA: Revista de la Asociación Española de Contabilidad y Administración de Empresas, AECA, Madrid, pág. 52.

Webb T. (2005): Call for papers. Symposium on Co-operative Accounting. Halifax (Canada), 2-4 de junio.

Young Foundation (2006): Social Innovation: what is it, why it matters, how it can be accelerated, London, Basingstoke Press.

Zelaia Ulibarri, Adrián (1997): Kooperatibak Euskal Herrian, Udako Euskal Unibertsitatea, Bilbao.

Zendoia, Andoni (2009): "Hezkuntza, gizarte kudeaketarako ondasuna», BERRIA, 20 de octubre de 2009, Andoain, Gipuzkoa, pág. 5. 